\title{
Sex Pheromone Responses of the Oriental Beetle (Coleoptera: Scarabaeidae)
}

\author{
HENRY T. FACUNDO, AIJUN ZHANG, PAUL S. ROBBINS, STEVE R. ALM, ${ }^{1}$ \\ CHARLES E. LINN, JR., MICHAEL G. VILLANI, AND \\ WENDELL L. ROELOFS
}

Department of Entomology, New York State Agricultural Experiment Station, Cornell University, Geneva, NY 14456

\begin{abstract}
Environ. Entomol. 23(6): 1508-1515 (1994)
ABSTRACT The synthetic female sex pheromone of the oriental beetle, Anomala orientalis Waterhouse, was evaluated in the field and in a sustained-flight tunnel. In a 2-wk period, $>150,000$ beetles were captured on three golf course fairways in Connecticut. Contrary to earlier reports that these beetles are most active during the warm, sunny portions of the day, we observed that peak activity occurs around sunset. Ten micrograms of either (Z)-7-tetradecen-2-one or an 89/11 (Z/E) blend on a rubber septum was found to be the minimum concentration with which no significant decrease in catch was observed in the field. There was no discrimination between $\mathrm{Z}$ and the blend at $1 \mu \mathrm{g}$ and higher concentrations, but the $\mathbf{E}$-isomer alone trapped significantly fewer beetles than either $\mathbf{Z}$ alone or the blend. These results are consistent with the flight tunnel data. The effects of temperature and light intensity on the mating behavior of $A$. orientalis also are discussed.
\end{abstract}

KEY WORDS oriental beetle, Anomala orientalis, sex pheromone responses

IN THE NORTHEASTERN United States, landscape plants are subject to intense feeding pressure from a complex of scarab species, including the Japanese beetle, Popillia japonica Brunner von Waltenwyl; the European chafer, Rhizotrogus (Amphimallon) majalis (Razoumowsky); and the oriental beetle, Anomala orientalis Waterhouse (Tashiro 1987). Of these three species, the Japanese beetle is considered the key pest and has received most of the research attention even though a significant amount of the damage attributed to this species in the Northeast is actually caused by the oriental beetle. Although it was not until 1920 that the first oriental beetle adults were collected from a nursery in New Haven, CT, its introduction to the U.S. mainland, presumably through infested balled nursery stock imported directly from Japan, might have been as early as 1911 (Friend 1929). At present, it has been reported in six northeastern states as well as North Carolina and Hawaii. However, because of the cryptic nature of adults and the similarity of its grub stage to other scarab species in the complex, the true range of this insect is not known.

The oriental beetle is the most important insect pest of turfgrass in the Long Island region of New York State, northern New Jersey, and Con-

i Department of Plant Sciences, University of Rhode Island, Kingston, RI 02881. necticut. Turfgrasses now cover an estimated 10.1 to 12.1 million ha in the United States, and turfgrass culture is at least a $\$ 25$ billion per year industry (Potter \& Braman 1991). Despite the considerable efforts expended and cost incurred, the control of scarabs that damage turfgrass, landscape plantings, and horticultural commodities has been inconsistent since the loss of the cyclodiene insecticides (Harris 1982, Baker 1986, Cowles \& Villani 1994).

The elucidation of the oriental beetle pheromone system could provide a good pest management tool for monitoring, which is essential to an integrated pest management program, in terms of detection and evaluation of local populations and treatment timing (Potter \& Haynes 1993). The use of this sensitive species-specific monitoring device is imperative because mixed soil populations of Japanese and oriental beetle grubs are often thought to be entirely Japanese beetles because only Japanese beetle adults are seen feeding or are caught in commercial Japanese beetle traps. However, oriental beetle grubs have a wider host range than other annual scarab species and, therefore, may cause significantly greater damage on a per insect basis to most horticultural commodities (M.G.V. \& R. Broadway, unpublished data). Additionally, oriental beetle grubs show different susceptibility to insecticides (Baker 1986), insect growth regulators (M.G.V., unpublished data) and commercial 
milky disease (Klein 1988) than does the Japanese beetle.

In Japan, the sex pheromone of the oriental beetle (Japanese name, semadarakogane), Exomala orientalis, has been identified as a 7:1 mix of $(Z)$ - and (E)-7-tetradecen-2-one (Leal 1993). It has not been established if this is the same species as that occurring in the United States (Leal et al. 1994). Nonetheless, the same compounds were identified as components of the sex pheromone of the latter (Zhang et al. 1994).

This article describes the responses of the male to the female sex pheromone of the U.S. (mainland) population of oriental beetle in the flight tunnel and in the field. Some aspects of beetle chemical ecology are also discussed.

\section{Materials and Methods}

Insects. Male beetles were 4-10 d postemergence. These insects were collected as second instars in Norwich, CT during the fall 1992 season and stored in boxes with soil and sod at $10^{\circ} \mathrm{C}$ until needed. When adults were needed, the larvae were transferred to individual cups with soil and sod and reared at $25^{\circ} \mathrm{C}$, with a photoperiod of 16:8 (L:D) $\mathrm{h}$ to allow final larval development, pupation, and emergence.

Chemicals. The chemicals, $(\mathrm{Z})$ - and (E)-7-tetradecen-2-one, were synthesized from $(Z)$ - and (E)-6-tridecen-1-ol, respectively, by three steps. The isolation, identification, and synthesis of these compounds are described in detail in Zhang et al. (1994). Purity of each isomer was found to be $>99.5 \%$ as determined by gas chromatography with flame ionization detector. The different concentrations and ratios of the Z- and E-isomers were prepared in glass-distilled hexane. Sources were prepared by pipetting $100 \mu \mathrm{l}$ of an appropriate concentration of the chemical onto a rubber septum and letting the solvent evaporate for $2 \mathrm{~h}$ in a fume hood.

Flight Tunnel Tests. A sustained-flight tunnel was used to determine the optimum concentration to be used in the field (Miller \& Roelofs 1978). These tests were performed under photophase conditions ( $700 \mathrm{lux}, 26.5-28.0^{\circ} \mathrm{C}, 66.5-$ $71.0 \% \mathrm{RH}, 0.4 \mathrm{~m} / \mathrm{s}$ air current).

Each male was removed from its emergence cup and transferred to individual inverted small glass jar with moist paper towel underneath $1 \mathrm{~h}$ before the test.

The chemical sources were placed one at a time at the upwind end of the tunnel. A small screen cage with a male beetle in it was positioned downwind on a platform at the same height as the source. The open end of the cage was directed upwind so that the beetle was free to move up and out of the cage. Male response or nonresponse was recorded. The behavioral responses scored were the following: (1) activation; as evidenced by restlessness and waving of antennae (with lamellae open and directed upwind) and forelegs, followed by walking upwind and preliminary wing extension and flapping; (2) taking fight; (3) casting (wide zigzag flight); (4) locking onto the plume (less zigzag upwind flight); (5) approaching the source (scored when a beetle was $\approx 10 \mathrm{~cm}$ from the source); and (6) touching the source. Each beetle was given up to $1 \mathrm{~min}$ to activate. Beetles that took flight but were not able to complete the sequence were given three tries and were scored according to the most complete sequence exhibited. Data were analyzed using the method of adjusted significance levels for proportions (Ryan 1960, $P<$ 0.05)

Field Tests. All field tests were conducted on the Norwich Community Golf Course in Norwich, CT between 29 June and 11 July 1993. Experiment 1 was set up on two adjacent fairways known to be infested with oriental beetle grubs during the fall 1992 season. Japanese beetle traps (Trece, Salinas, CA) were used, with a rubber septum pheromone source fixed between the four vanes. The rubber septa were impregnated with the following different chemical treatments: 100,300 , and $1,000 \mu \mathrm{g}$ of the $\mathrm{Z} / \mathrm{E}(89 / 11)$ blend, and $100 \mu \mathrm{g}$ of each of $\mathrm{Z}$ and $\mathrm{E}$ isomers. In addition to these five treatments, three live females in a small, sealed screen cage placed in the space between the four vanes of the trap, and a blank rubber septum were included as controls. The receptacle for trapped insects was buried to the ground with the aid of a cup cutter so that only the yellow funnel and vanes were visible above ground. The pheromone sources were $\approx 20 \mathrm{~cm}$ from the ground.

The traps were arranged in a randomized complete block design with five blocks at the sides of, and parallel to, the fairways. The first two blocks were placed at least $20 \mathrm{~m}$ apart at the northwest side of the site. Blocks 3 and 4 were at the area between the two fairways also at least $20 \mathrm{~m}$ apart, while the fifth block was at the southeast side. Each fairway was $\approx 80 \mathrm{~m}$ wide. Woody areas flanked the experimental site at both the northwest and southeast sides. Within a block, the traps were set in a straight line at 10-m intervals.

Traps were monitored at 2-h intervals for $24 \mathrm{~h}$. Beetles caught in each trap were poured into a self-sealing plastic bag containing a piece of tissue paper wet with ethyl acetate. The beetles were counted later. Soil and air temperatures were also recorded during each monitoring schedule. Soil temperatures obtained were at $5 \mathrm{~cm}$ below ground level, whereas air temperatures were recorded at the level of the source.

Subsequent tests using lower concentrations were also performed in the same area. Experiment 2 had the following treatments: $100 \mu \mathrm{g}$ of the blend $(89 / 11, \mathrm{Z} / \mathrm{E}), 10 \mu \mathrm{g}$ also of the blend, $10 \mu \mathrm{g}$ of $\mathrm{Z}$, and a blank. In the third experiment, 
the dose was reduced to $1 \mu \mathrm{g}$ of the blend, $1 \mu \mathrm{g}$ of $\mathrm{Z}, 10 \mu \mathrm{g}$ of the blend, and a blank. The traps for these experiments were set $20 \mathrm{~m}$ apart also in a randomized complete block design as described above. Monitoring for both experiments was carried out four times a day at 1000, 1400, 1800 , and 2200 hours for three consecutive days. Rerandomization within blocks was performed every day after the 1000-hours monitoring.

Data for all three experiments were transformed using $\log (x+1)$, then analyzed using analysis of variance and Fisher's protected least significant difference for multiple comparison through SYSTAT (Systat 1992) at $P=0.05$ significance level.

A mark-and-recapture experiment was performed to investigate the possibility of a separate male population responding selectively to the $\mathrm{E}$ isomer. Male beetles caught in $100 \mu \mathrm{g} \mathrm{E}$ traps from the first experiment were individually marked with a red marking pen. One hundred individuals were released at 1100 hours from a spot about $20 \mathrm{~m}$ downwind from two traps $10 \mathrm{~m}$ apart, one baited with $100 \mu \mathrm{g} \mathrm{E}$ and the other with $100 \mu \mathrm{g} \mathrm{Z}$. The traps were inspected at 1500 and 1900 hours of the same day for recaptured marked beetles. Two trials were performed at different sites. Data were analyzed using the method of adjusted significance levels for proportions (Ryan 1960, $P<0.05$ ).

In another fairway, also known to harbor a good population of oriental beetles, four blacklight traps (All Weather Insect Trap Model $29 \mathrm{~W}$ 6002 with Inverter/12V DC Model 29 W 6010 and a 12-V battery power source, Ward's, Rochester, NY), each with a receptacle containing soapy water, were set up to check the flight activity of the beetles. Two of these traps were modified to serve as pheromone traps by placing a rubber septum baited with $100 \mu \mathrm{g}$ of the blend in a hole on one of the vanes, $8 \mathrm{~cm}$ above the mouth of each trap, with the lights off. Initially, one trap of each type was hung at $\approx 2.5 \mathrm{~m}$ from the ground using sturdy poles, while keeping the other one at ground level. Because only a small number of beetles were caught at the $2.5-\mathrm{m}$ height, all four traps were later set at ground level. Because the mouth of the receptacle containing soapy water was $\approx 30 \mathrm{~cm}$ above ground, beetles had to fly this height to be caught in the trap. The pheromone traps were separated from the blacklight traps by a distance of $50 \mathrm{~m}$, whereas traps of the same type were $20 \mathrm{~m}$ apart. All four were arranged in a straight line parallel to a fairway at one side and a woody area at the other side.

Monitoring commenced at 1300 or 1400 hours (traps were set at 1200 and 1300 hours, respectively) and continued hourly until 2300 or 2400 hours. Besides the number of males, the approximate number of females caught in each trap was also noted. Soil and air temperatures at each

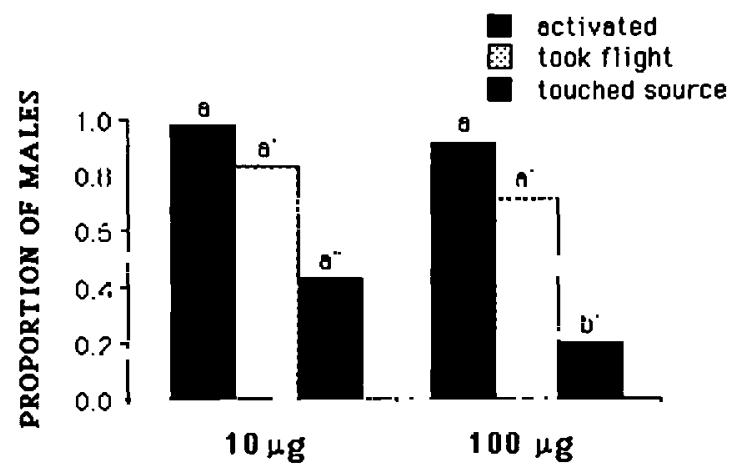

Fig. 1. Behavioral assay of two dosages of the $\mathrm{Z} / \mathrm{E}$ blend $(90 / 10)$ using a sustained-flight tunnel $\left(n_{10}=54\right.$; $n_{100}=56$ ). A blank septum elicits no activation from these beetles. Comparison is between the same response stage (identically colored bars) of the two dosages. Identically shaded bars with the same letter (and superscript) are not significantly different $(P<0.05)$.

monitoring were recorded as well. Overnight catch (i.e., from 2400 to 1200 hours) was noted. After two monitoring days, the positions of the two types of traps were switched. Data were analyzed using Cox and Stuart test for trend (Conover 1980).

\section{Results and Discussion}

Flight Tunnel Tests. The sequence of behavioral responses to the female pheromone as described above is similar to that described by Domek et al. (1990) for the male green June beetle, Cotinis nitida (L.).

Ten nanograms of $\mathbf{Z}$ on a filter paper was previously found to be the optimum concentration to which a high proportion of males respond positively, compared with lower concentrations. The level of response from males to this concentration was comparable to that when three to six females were used as the source (Zhang et al. 1994).

Using a rubber septum, $1 \mu \mathrm{g}$ of the $90 / 10(\mathrm{Z} / \mathrm{E})$ blend elicited activation (restlessness) from $67 \%$ of the males tested, but $<10 \%$ got within $30 \mathrm{~cm}$ of the source. With $10 \mu \mathrm{g}$ of the blend, $43 \%$ of the males tested touched the source and $98 \%$ activated. However, there was a significant decline in the proportion of males that touched the source with $100 \mu \mathrm{g}$ of the same blend, even though there was no significant decrease in the proportion that activated and took flight (Fig. 1). Therefore, $10 \mu \mathrm{g}$ of the $90 / 10(\mathrm{Z} / \mathrm{E})$ blend is apparently more effective than $100 \mu \mathrm{g}$ of the same in the flight tunnel conditions. It appeared that arrestment of flight occurred as the male approached the $100 \mu \mathrm{g}$ source, thus preventing a number of them from touching it. Touching the source from flight, however, is a stringent criterion for a complete positive response of the male, 

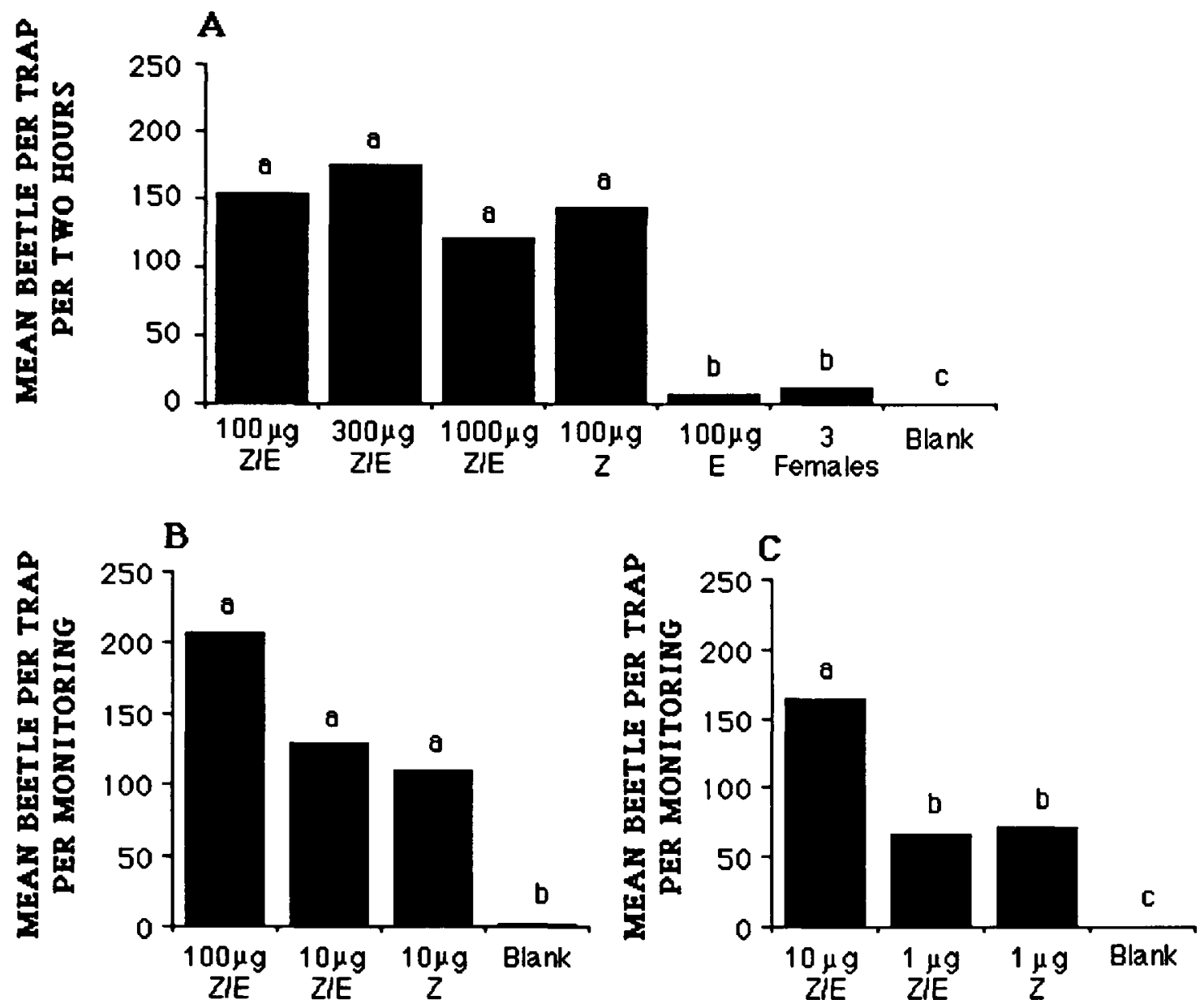

Fig. 2. Male responses to different concentrations and isomeric ratios of the synthetic pheromone in the field. A-C, experiment 1,2 , and 3 , respectively. Treatments with the same letters are not significantly different $(P<$ $0.05)$.

considering that in the natural conditions it was observed that males normally land several centimeters away from a female and then walk toward the female, presumably using visual cues as well.

Field Tests. After three successive experiments involving different concentrations (Fig. $2 \mathrm{~A}-\mathrm{C}), 10 \mu \mathrm{g}$ of either $\mathrm{Z}$ or the $89 / 11(\mathrm{Z} / \mathrm{E})$ blend on a rubber septum was found to be the minimum concentration with which no significant decrease in catch was observed. This was similar to the results in the flight tunnel wherein the same concentration was found to be more attractive than lower concentrations. However, the apparent advantage of $10 \mu \mathrm{g}$ over $100 \mu \mathrm{g}$ was not seen in the field. The results illustrate the usefulness of the flight tunnel in determining an active range of pheromone load rates before the field season.

At $1 \mu \mathrm{g}$ and higher concentrations, males did not discriminate between the $\mathrm{Z}$ and $89 / 11 \mathrm{Z} / \mathrm{E}$ blend (Fig. $2 \mathrm{~A}-\mathrm{C}$ ). However, there were signif- icantly more beetles caught in either $\mathrm{Z}$ or $\mathrm{Z} / \mathrm{E}$ traps than in traps baited with $\mathrm{E}$ (Fig. 2A). These findings are consistent with the results of the flight tunnel experiments, in that there was no discrimination between $\mathrm{Z}$ and the blend in the 50-ng level on filter paper, and only one male flew towards the 50-ng E source out of the many beetles tested in many trials (Zhang et al. 1994). Similar field results were obtained by Leal et al. (1994) on the Japanese population of E. orientalis.

Data from the mark-and-recapture experiments in the field suggest that there is not a separate male population that is narrowly tuned to the $\mathbf{E}$ isomer. Instead, males caught in the pure $E$ traps were receptive to a wider range of isomeric ratios, because a significantly higher proportion of the supposed $E$ males were recaptured in the $\mathrm{Z}$ trap (mean of 13 marked beetles versus only 1 in $E$ of the 100 released in each trial). Likewise, in the flight tunnel almost all beetles (9 of 11) collected from $100 \mu \mathrm{g} E$ traps in 
the field and brought to Geneva responded to the $\mathrm{Z}$ isomer, and the three beetles that were responsive to the $\mathrm{E}$ isomer in the flight tunnel also responded to $Z$.

Contrary to the claim that oriental beetles are most active during the warm, sunny portions of the day and that most flights occur between 0800 to 1600 hours (Hallock 1930, 1933, Tashiro 1987), our data suggest that they are crepuscular because we obtained the highest catch around sunset. Data for the synthetic pheromone traps (Figs. 3A and $4 \mathrm{~A}-\mathrm{D}$ ), the live-females traps (Fig. 3B), and the blacklight traps (Fig. 4 A-D), clearly support this conclusion. Light intensity may play an important role in the mating behavior of this beetle. In the darkened flight tunnel ( $0.5 \mathrm{lux})$, it was noted that females from photophase elicited positive response from males, whereas females from scotophase did not (Zhang et al. 1994). The onset of scotophase might be an important cue for females to release the pheromone.

Bianchi (1935), during his study on the Hawaiian population of the oriental beetle, observed a similar flight activity pattern. Periods of increased activity, when all or most of the beetles rise in flight simultaneously, occurs when passing clouds cover the sun (in which case flight activity lasts only for a few minutes) or when the sun is hidden as a consequence of its downward path below the horizon (in which case it lasts longer with varying but gradually diminishing intensity until darkness sets in). Bianchi associated these events with a sudden drop in atmospheric temperature and conjectured that males fly in response to this stimulus or to a stimulus that coincides with it. This is opposite to the Japanese beetle preference for very warm and sunny conditions for peak flight (Lacey et al. 1994). Bianchi reported that although there were occasions when several males flew (or crawled or both) toward a common point, a female, or a mating pair, these were mostly attributed to the gregarious instinct of males. In other hours of the day, males are seen resting on weeds, trash, or leaves of sugarcane plants, while females are usually seen feeding on nearby flowers. On the other hand, Friend (1929) reported difficulty in finding oriental beetle adults in New Haven because they do not fly far or very frequently. In 1926, twelve scouts secured 2,402 adults in $2 \mathrm{mo}$, which, Friend noted, is a small number compared with the number of larvae present in any one infested lawn.

In the current study, we also had difficulty locating adults during the day in an area without the traps even though a large population of larvae was found at the same location during the fall 1992 season. Only five males in separate occasions were discovered perched on grasses or shrubs during a week of scouting at the same area (an average of $2-3 \mathrm{~h}$ every afternoon), com- pared with a mean trap (100 $\mu \mathrm{g}$ of the blend) catch of $\approx 1,000$ beetles per day.

It is evident in Figs. 3 and 4 that peak flight activity starts in the afternoon, at least in areas with the pheromone traps, and continues until shortly after sunset (2100 hours). Blacklight traps obtained the highest catch at 2100 hours, whereas catch in other hours of the day, including the overnight catch, rarely exceeds five beetles per trap. It is at this time (immediately before, during, and immediately after sunset) that more beetles of both sexes were encountered on the turf, crawling or resting on the edge of grass blades. This is in addition to those that were already flying toward the traps. However, we cannot yet explain the distinct drop in the number of beetles caught in the pheromone traps just before sunset ( $\approx 1900$ or 2000 hours).

Temperature, apparently, has a profound effect on beetle activity and consequently on trap catch. This effect is clearly illustrated in the contrast between the temperature and catch data from 2 and 5 July (Fig. $4 \mathrm{~A}$ and $\mathrm{C}$ ) and that from 4 and 6 July (Fig. 4 B and D). Temperatures were more or less favorable on 4 and 6 July and, thus, the peak ( 2100 hours) was evident in both days. However, on 2 July, the daytime and nighttime temperatures were lower and, thus, there was no distinct peak at all. For 5 July, the temperature during the day was high, but at $\approx 2000$ hours the temperature dipped below $20^{\circ} \mathrm{C}$ and went down even further later in the evening. As a consequence, there was a peak at 1800 hours but there was none at 2100 hours. There were positive correlations between mean air and mean soil temperatures and total daily catch $(P=0.06)$ for both blacklight and pheromone traps.

The above field observations are consistent with those in the flight tunnel, in that optimal flight performance is dependent on higher temperatures and an acclimation period of at least $24 \mathrm{~h}$ at $25^{\circ} \mathrm{C}$.

Although wind velocity in the field was not quantitatively measured, very strong wind seemed to inhibit flight, whereas a slight breeze seemed to facilitate pheromone source finding of the male. Further studies are needed to elucidate the influence of environmental factors on this pheromone communication system of the oriental beetle.

Our field results show that this newly synthesized chemical is very potent considering that a relatively small dosage $(100 \mu \mathrm{g})$ caught an average of 1,000 beetles per trap per day. It can certainly aid us in understanding some aspects of the chemical ecology of this beetle. In fact, we now know (Fig. 3) that males do respond to the synthetic pheromone $24 \mathrm{~h}$ a day (a few males were still seen crawling toward the traps even in the coolest part of the night) and it might be that their activity is just constrained by unfavorable environmental conditions particularly low (and 

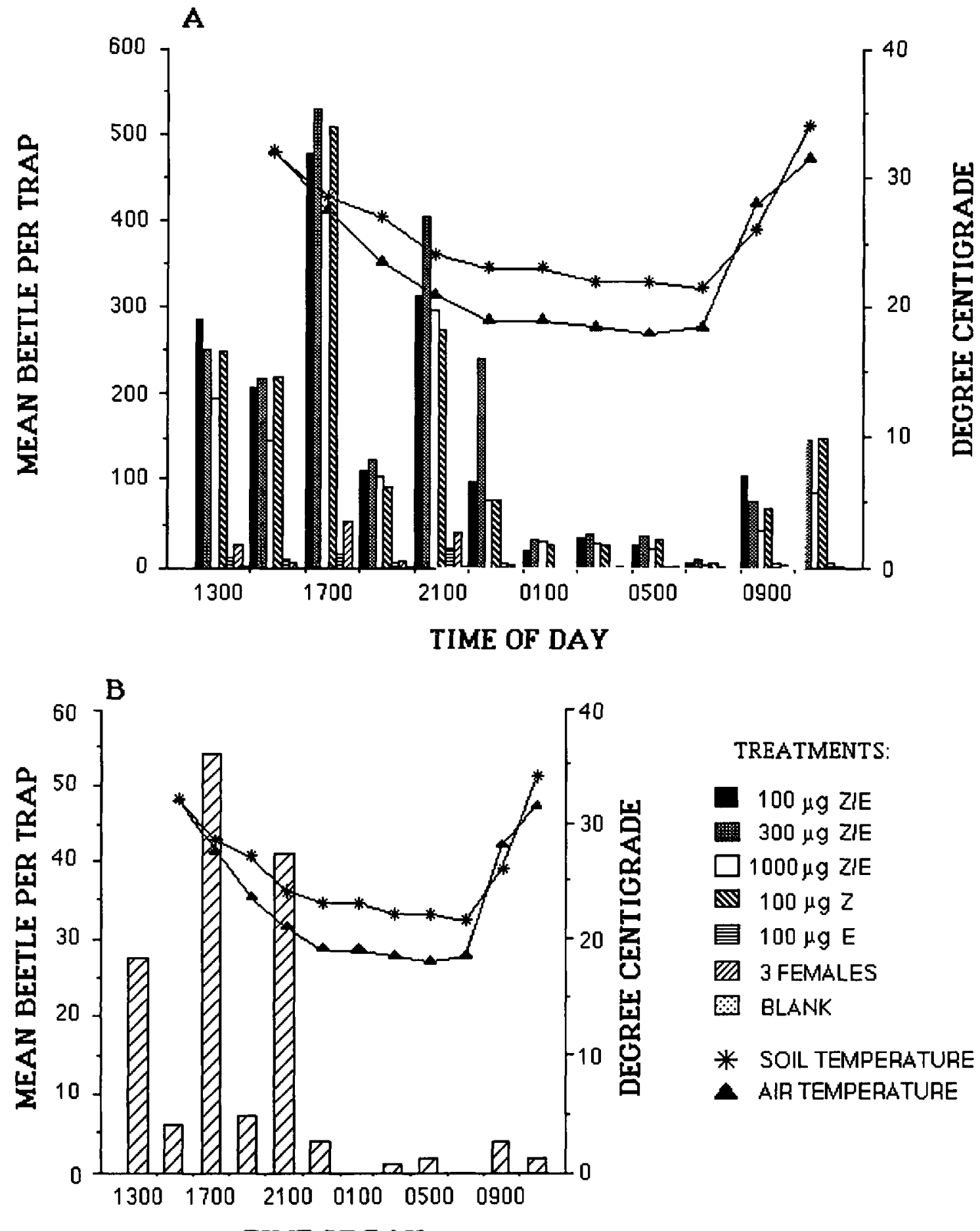

\section{TIME OF DAY}

Fig. 3. Beetle temporal response to the synthetic pheromone. A, experiment 1 data with all seven treatments included; B, traps baited with three live females only. Time sequence is according to actual monitoring schedule. Temperature data for $13 \mathrm{~h}$ were not obtained.

possibly very high) temperatures. Therefore, it appears that males have a wide window of receptivity and perhaps the circadian rhythm of pher- omone release by females ultimately determines the male time of activity. Thus, this synthetic pheromone has great potential for use in oriental 
A

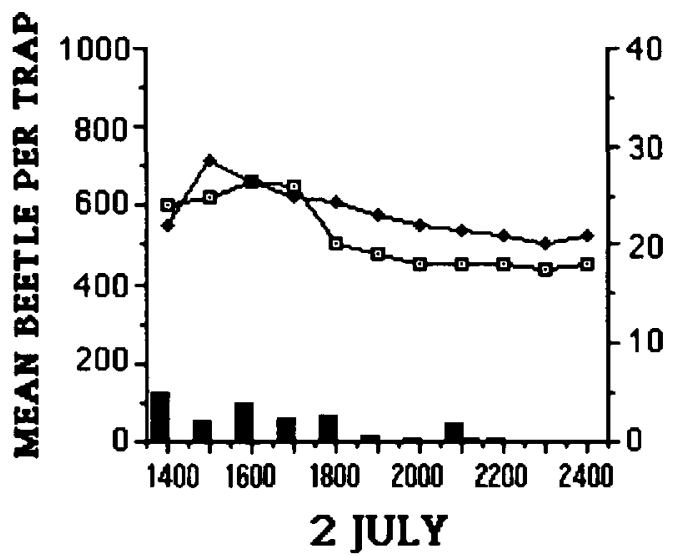

C

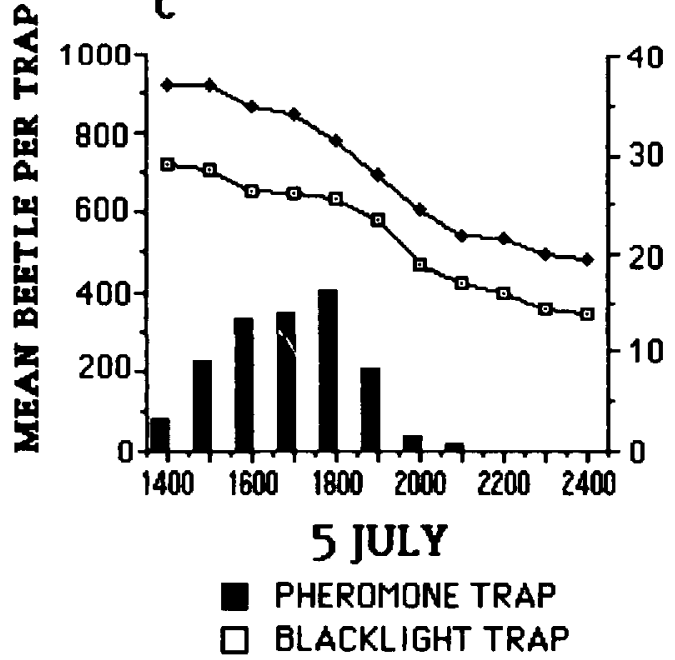

B

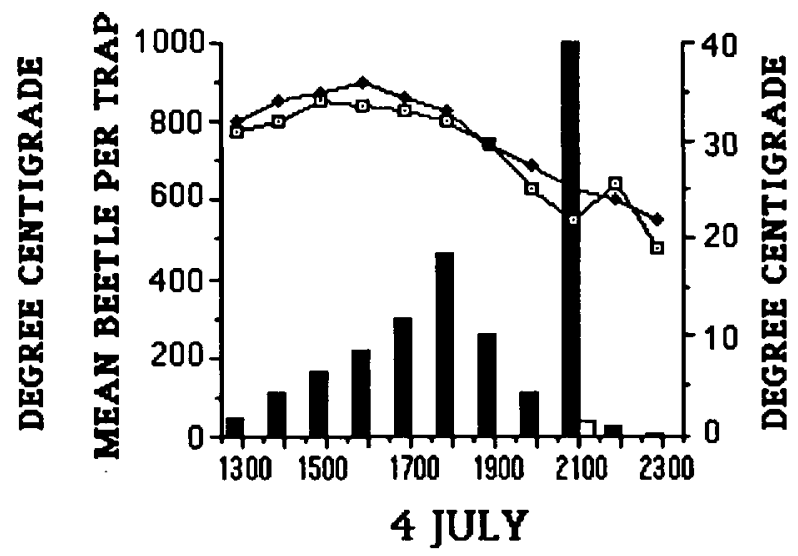

D

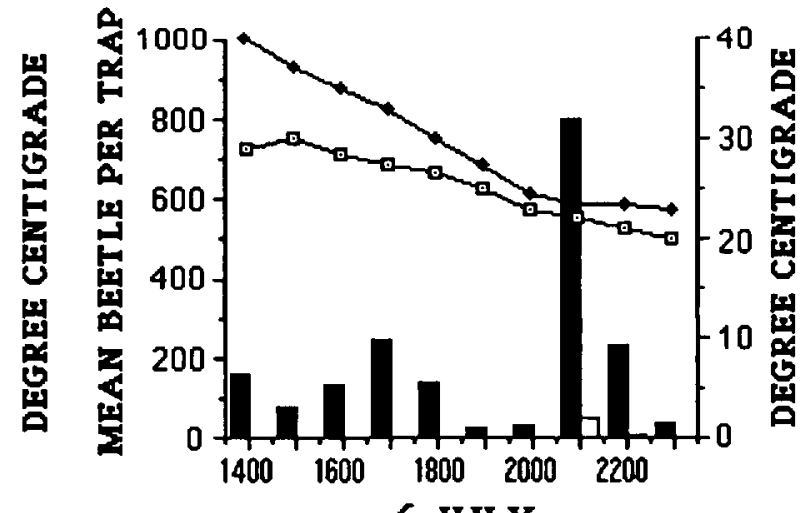

6 JULY

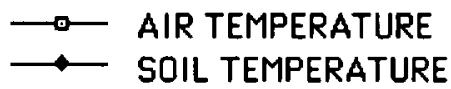

Fig. 4. Beetle flight activity as manifested in the hourly catch of the blacklight and pheromone traps from early afternoon until midnight. A-D , 2, 4, 5 , and 6 July, respectively. Total daily catch was positively correlated to mean air and mean soil temperatures for both types of trap $(P=0.06)$.

beetle monitoring and trapping, especially because adults are inconspicuous during the day and increasing populations may be left undetected until severe damage to turf is already done.

\section{Acknowledgments}

We thank Bruce Morse and the staff of the Norwich Community Golf Course for their support and for allowing us to use the golf course and its facilities. We also thank David James, Nancy Chrestensen, and Jill McCutcheon for their assistance during the field tests. The stands for the blacklight traps were constructed by Charles Dawson. Insect collecting and rearing were done by Nancy Consolie, Carrie Roach, Robert $\mathrm{H}$. Jarecke, Jr., Luann Preston-Wilsey, and Wendy Heusler. Trece (Salinas, CA) donated the Japanese beetle traps. This study was funded, in part, by NRI/CGP grant 92-37302-7657.

\section{Referenceś Cited}

Baker, P. B. 1986. Responses by Japanese and oriental beetle grubs (Coleoptera: Scarabaeidae) to bendiocarb, chlorpyrifos and isofenphos. J. Econ. Entomol. 79: 452-454.

Bianchi, F. A. 1935. Investigations on Anomala orientalis Waterhouse at Oahu Sugar Company, Hawaii. Plant. Rec. 39: 234-255.

Conover, W. J. 1980. Practical nonparametric statistics, 2nd ed. Wiley, New York.

Cowles, R. S. \& M. G. Villani. 1994. Influence of soils on Japanese beetle chemical and biological insecticides. J. Econ. Entomol. 87: 1014-1021.

Domek, J. M., J. H. Tumlinson \& D. T. Johnson. 1990. Responses of male green June beetles Cotinis nitida (L.) (Coleoptera: Scarabaeidae) to female volatiles in a fight tunnel. J. Insect Behav. 3: 271276.

Friend, R. B. 1929. The Asiatic beetle in Connecticut. Conn. Agric. Exp. Stn. Bull. 304: 585-664. 
Hallock, H. C. 1930. The Asiatic beetle, a serious pest in lawns. U.S. Dep. Agric. Circ. 117: 7.

1933. Present status of two asiatic beetles (Anomala orientalis and Autoserica castanea) in the United States. J. Econ. Entomol. 26: 80-85.

Harris, M. 1982. Factors influencing the toxicity of insecticides in soil, pp. 47-52. In H. D. Niemczyk \& B. G. Joyner [eds.], Advances in turfgrass entomology. Chemlawn, Columbus, $\mathrm{OH}$.

Klein, M. G. 1988. Pest management of soilinhabiting insects with microorganisms. Agric. Ecosyst. Environ. 24: 337.

Lacey, L. A., J. J. Amaral, J. Coupland \& M. G. Klein. 1994. The influence of climatic factors on the flight activity of the Japanese beetle (Coleoptera: Scarabaeidae): Implications for use of a microbial control agent. Biol. Control (in press).

Leal, W. S. 1993. (Z)- and (E)-Tetradec-7-en-2-one, a new type of sex pheromone from the Oriental beetle. Naturwissenschaften 80: 86-87.

Leal, W. S., M. Hasegawa, M. Sawada \& M. Ono. 1994. Sex pheromone of the Oriental beetle, $E x$ omala orientalis: identification and field evaluation. J. Chem. Ecol. 20: 1705-1718.

Miller, J. R. \& W. L. Roelofs. 1978. Sustained-flight tunnel for measuring insect responses to windborne sex pheromones. J. Chem. Ecol. 4: 187-198.
Potter, D. A. \& S. K. Braman. 1991. Ecology and management of turfgrass insects. Annu. Rev. Entomol. 36: 383-406.

Potter, D. A. \& K. F. Haynes. 1993. Field-testing pheromone traps for predicting Masked Chafer (Coleoptera: Scarabaeidae) grub density in golf course turf and home lawns. J. Entomol. Sci. 28: 205-212.

Ryan, J. A. 1960. Significance tests for multiple comparisons of proportions, variances, and other statistics. Psychol. Bull. 57: 318-328.

SYSTAT. 1992. SYSTAT: Statistics, Version $5.2 \mathrm{ed}$ Systat. Evanston, IL

Tashiro, H. 1987. Turfgrass insects of the United States and Canada. Comell University Press, Ithaca, NY.

Zhang, A., H. T. Facundo, P. S. Robbins, C. E. Linn, Jr., J. L. Hanula, M. G. Villani \& W. L. Roelofs. 1994. Identification and synthesis of the female sex pheromone of the oriental beetle, Anomala orientalis (Coleoptera: Scarabaeidae). J. Chem. Ecol. (in press).

Received for publication 7 March 1994; accepted 21 June 1994. 